\title{
The Radical SAM Enzyme HydG Requires Cysteine and a Dangler Iron for Generating an Organometallic Precursor to the [FeFe]-Hydrogenase H-Cluster
}

\author{
Daniel L. M. Suess ${ }^{\dagger}$, Cindy C. Pham ${ }^{\dagger}$, Ingmar Bürstel ${ }^{\ddagger}$, James R. Swartz ${ }^{\ddagger}$, , Stephen P. \\ Cramer $^{*}, \dagger$, and R. David Britt ${ }^{*} \dagger$ \\ tDepartment of Chemistry, University of California, Davis, Davis, California 95616, United States \\ ¥Department of Chemical Engineering, Stanford University, Stanford, California 94305, United \\ States \\ §Department of Bioengineering, Stanford University, Stanford, California 94305, United States
}

\begin{abstract}
Three maturase enzymes- $\mathrm{HydE}, \mathrm{HydF}$, and $\mathrm{HydG}$ - synthesize and insert the organometallic component of the [FeFe]-hydrogenase active site (the H-cluster). HydG generates the first organometallic intermediates in this process, ultimately producing an $\left[\mathrm{Fe}(\mathrm{CO})_{2}(\mathrm{CN})\right]$ complex. A limitation in understanding the mechanism by which this complex forms has been uncertainty regarding the precise metallocluster composition of HydG that comprises active enzyme. We

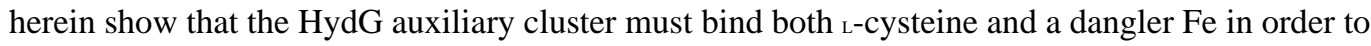
generate the $\left[\mathrm{Fe}(\mathrm{CO})_{2}(\mathrm{CN})\right]$ product. These findings support a mechanistic framework in which a $\left[(\mathrm{Cys}) \mathrm{Fe}(\mathrm{CO})_{2}(\mathrm{CN})\right]^{-}$species is a key intermediate in $\mathrm{H}$-cluster maturation.
\end{abstract}

\begin{abstract}
The redox interconversion of protons and $\mathrm{H}_{2}$ is central to a number of metabolic processes and to the generation of solar fuels from sunlight and water. $[\mathrm{FeFe}]$ hydrogenases are the most active biological catalysts for $\mathrm{H}_{2}$ production ${ }^{1}$ and employ a unique active site-the $\mathrm{H}$ cluster - which consists of a conventional $[4 \mathrm{Fe}-4 \mathrm{~S}]_{\mathrm{H}}$ subcluster bridged via a cysteine residue to a structurally unique $[2 \mathrm{Fe}]_{\mathrm{H}}$ subcluster $($ Scheme $1 \mathrm{~A})$. The organometallic $[2 \mathrm{Fe}]_{\mathrm{H}}$ subcluster is synthesized from inorganic and organic precursors (Scheme 1A) in a complex process performed by three maturase enzymes: HydE, HydF, and HydG. ${ }^{2} \mathrm{HydF}$ is thought to serve as a scaffold for the assembly of a di-iron precursor that is inserted into apo-HydA (which does not contain the $[2 \mathrm{Fe}]_{\mathrm{H}}$ subcluster) to produce active holo-HydA. ${ }^{3} \mathrm{HydE}$ and HydG are members of the radical $S$-adenosyl-L-methionine (SAM) family of enzymes ${ }^{4}$ and are involved in the synthesis of this di-iron precursor. In particular, HydG is responsible for
\end{abstract}

\footnotetext{
*Corresponding Authors: rdbritt@ucdavis.edu, spjcramer@ucdavis.edu. ASSOCIATED CONTENT

Supporting Information

The Supporting Information is available free of charge on the ACS Publications website at DOI: 10.1021/jacs.5b12512.

Materials and methods (PDF)

The authors declare no competing financial interest.
} 
building the first organometallic intermediates to the $[2 \mathrm{Fe}]_{\mathrm{H}}$ subcluster and is the subject of this Communication.

HydG reductively cleaves SAM to generate a $5^{\prime}$-deoxyadenosyl radical $\left(5^{\prime}\right.$-dA $\bullet$ ) that abstracts an $\mathrm{H}$-atom from substrate $\mathrm{L}$-tyrosine (Tyr) (Scheme 1B). ${ }^{5}$ The resulting N-centered radical $^{6}$ undergoes $\mathrm{C}_{\alpha}-\mathrm{C}_{\beta}$ bond scission to give the 4-hydroxybenzyl radical $(4 \mathrm{HOB} \bullet$ ) as observed by EPR spectroscopy. ${ }^{7}$ The other fragment of the Tyr cleavage step, dehydroglycine (DHG), is transformed into $\mathrm{CO}$ and $\mathrm{CN}^{-} .8,9$ FTIR spectroscopic studies have demonstrated that these Tyr-derived diatomics comprise the $[2 \mathrm{Fe}]_{\mathrm{H}}$ subcluster, ${ }^{10}$ and time-resolved FTIR spectroscopic studies have shown that organometallic species are generated when HydG is mixed with Tyr, SAM, and dithionite (DTH). ${ }^{11} \mathrm{In}$ addition, ${ }^{57} \mathrm{Fe}$ ENDOR spectroscopic studies have shown that $\mathrm{Fe}$ in the $[2 \mathrm{Fe}]_{\mathrm{H}}$ subcluster is derived from HydG. ${ }^{11}$ Taken together, these studies point to an $\left[\mathrm{Fe}(\mathrm{CO})_{2}(\mathrm{CN})\right]$ species produced by HydG as a key synthon in H-cluster biosynthesis. ${ }^{11}$

In order to assess the mechanism by which the $\left[\mathrm{Fe}-(\mathrm{CO})_{2}(\mathrm{CN})\right]$ species is formed, the starting metallocluster composition of $\mathrm{HydG}$ must be known. HydG harbors a [4Fe-4S] cluster that is bound by a $\mathrm{CX}_{3} \mathrm{CX}_{2} \mathrm{C}$ motif near the $\mathrm{N}$ terminus ("[4Fe- $\left.4 \mathrm{~S}\right]_{\mathrm{RS}}$ ") as well as an auxiliary cluster that is bound by a $\mathrm{CX}_{2} \mathrm{CX}_{22} \mathrm{C}$ motif near the $\mathrm{C}$ terminus; the $[4 \mathrm{Fe}-4 \mathrm{~S}]_{\mathrm{RS}}$ cluster is responsible for SAM cleavage, and the auxiliary cluster is thought to be the site of $\left[\mathrm{Fe}(\mathrm{CO})_{2}(\mathrm{CN})\right]$ synthon formation. ${ }^{11}$ Four candidates for the starting auxiliary cluster structure and its transformation to the $\left[\mathrm{Fe}-(\mathrm{CO})_{2}(\mathrm{CN})\right]$ synthon have been proposed (Scheme 2): (a) a $[4 \mathrm{Fe}-4 \mathrm{~S}]_{\text {aux }}$ cluster, ${ }^{11}$ (b) a $[5 \mathrm{Fe}-5 \mathrm{~S}]_{\text {aux }}$ cluster, ${ }^{12}$ (c) a $[4 \mathrm{Fe}-4 \mathrm{~S}]_{\text {aux }}[(\mathrm{Cys}) \mathrm{Fe}]$ cluster $\left(\right.$ Cys $={ }_{\mathrm{L}}$-cysteine $),{ }^{13}$ and $(\mathrm{d})$ a $[4 \mathrm{Fe}-4 \mathrm{~S}]_{\mathrm{aux}}[(\mathrm{Hcy}) \mathrm{Fe}]$ cluster $\left(\mathrm{Hcy}=\mathrm{L}_{\mathrm{L}}\right.$-homocysteine $) .{ }^{14}$ Proposal (c) integrates earlier spectroscopic ${ }^{11,12}$ and structural ${ }^{12}$ findings with recent EPR spectroscopic studies which showed that the auxiliary cluster in as-isolated Shewanella oneidensis (So) HydG binds both a dangler Fe and Cys. ${ }^{13}$ These studies, combined with reports that Cys stimulates in vitro hydrogenase maturation, ${ }^{15,16}$ indicate a

$[4 \mathrm{Fe}-4 \mathrm{~S}]_{\mathrm{aux}}[(\mathrm{Cys}) \mathrm{Fe}]$ structure for the auxiliary cluster (Scheme $\left.2 \mathrm{c}\right) .{ }^{13}$ On the other hand, it has been reported that $\mathrm{CO}$ and $\mathrm{CN}^{-}$are generated in $\mathrm{HydG}$ samples that contain only a $[4 \mathrm{Fe}-4 \mathrm{~S}]_{\text {aux }}$ cluster structure. ${ }^{17}$ And it has been recently suggested that Hcy could substitute for Cys (Scheme 2d) ${ }^{14}$ though EPR spectroscopic studies have shown that structural

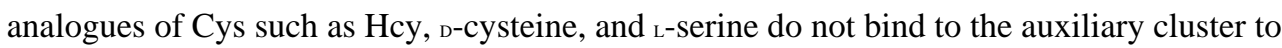
an appreciable extent. ${ }^{13}$ Regardless, there have been no reports in which the HydG auxiliary cluster structure has been rigorously correlated with the production of the $\left[\mathrm{Fe}(\mathrm{CO})_{2}(\mathrm{CN})\right]$ synthon, and as such, the importance of the dangler $\mathrm{Fe}$ and/or Cys in this process is uncertain. We herein use a combined EPR and FTIR spectroscopic approach to determine which starting auxiliary cluster structure(s) lead to $\left[\mathrm{Fe}(\mathrm{CO})_{2}(\mathrm{CN})\right]$ product formation.

When reduced by DTH, So HydG typically displays two EPR signals: an $S=1 / 2$ signal corresponding the $[4 \mathrm{Fe}-4 \mathrm{~S}]_{\mathrm{RS}}$ cluster and a distinctive $S=5 / 2$ signal corresponding to the $[4 \mathrm{Fe}-4 \mathrm{~S}]_{\text {aux }}[(\mathrm{Cys}) \mathrm{Fe}]$ cluster (Figure 1A). ${ }^{7,12,13,18}$ Other forms of the auxiliary cluster, including $[4 \mathrm{Fe}]$ forms that are deficient in the dangler $\mathrm{Fe}$ and $[5 \mathrm{Fe}]$ forms that are deficient in Cys, have been observed in HydG from other organisms ${ }^{12,17,19}$ and in some So HydG batches. ${ }^{13}$ It is not clear why some batches of HydG give rise to auxiliary cluster forms that are deficient in the dangler $\mathrm{Fe}$ and/or Cys, however all such forms are easily distinguished 
from the $[4 \mathrm{Fe}-4 \mathrm{~S}]_{\mathrm{RS}}$ and $[4 \mathrm{Fe}-4 \mathrm{~S}]_{\mathrm{aux}}[(\mathrm{Cys}) \mathrm{Fe}]$ clusters using EPR spectroscopy and may be converted to the $S=5 / 2[4 \mathrm{Fe}-4 \mathrm{~S}]_{\text {aux }}[(\mathrm{Cys}) \mathrm{Fe}]$ form by addition of $\mathrm{Fe}^{2+}$ and/or Cys. ${ }^{13}$

Four types of samples are required for distinguishing between the models in Scheme 2: one in which the dangler is not bound (sample 1), one in which Cys is not bound (sample 2), one in which both the dangler $\mathrm{Fe}$ and Cys are bound (sample 3), and one in which Cys is not bound and Hcy is present in solution (sample 4). Sample 3 may be trivially generated either by using HydG that is preloaded with both the dangler Fe and Cys or by reconstituting with Fe and/or Cys as necessary. ${ }^{13}$ Sample 1 may be generated by addition of EDTA to HydG in the presence of Cys. ${ }^{13}$ Although a method for reliably preparing Cys-deficient samples of HydG (e.g., samples 2 and 4) has not been reported, samples of HydG that are isolated in a Cys-deficient form (as determined by EPR spectroscopy) may be used for this purpose. ${ }^{13}$

Using the strategy outlined above, the four samples required for this study were generated from a single batch of Cys-deficient HydG. In the presence of DTH and SAM, EPR spectra of all samples show the expected SAM-bound $[4 \mathrm{Fe}-4 \mathrm{~S}]_{\mathrm{RS}}$ cluster signal with characteristic $g_{1}=2.01$ (Figure 2). Removal of the dangler Fe was effected by treatment with EDTA ${ }^{13}$ to give the dangler-free, $S=1 / 2[4 \mathrm{Fe}-4 \mathrm{~S}]_{\text {aux }}[\mathrm{Cys}]$ form with the characteristic $g_{1}=2.06$ feature (Figure 2, sample 1). When only treated with DTH and SAM (Figure 2, sample 2), this batch of HydG shows a number of signals indicating multiple $S=1 / 2[4 \mathrm{Fe}-4 \mathrm{~S}]_{\text {aux }}$ cluster forms (with $g_{1}>2.01$, seen as broad shoulders to the [4Fe-4S $]_{\mathrm{RS}}$ cluster signal), multiple $S=5 / 2$ $[5 \mathrm{Fe}]_{\text {aux }}$ forms (indicated by a sharp feature with $g_{\text {eff }}=5.2$ and other broad features), and a small amount of the $S=5 / 2[4 \mathrm{Fe}-4 \mathrm{~S}]_{\text {aux }}[(\mathrm{Cys}) \mathrm{Fe}]$ form with $g_{\text {eff }}=9.5$. Consistent with previous findings, ${ }^{13}$ addition of Cys simplifies the auxiliary cluster speciation (Figure 2, sample 3) with the major auxiliary cluster signal now corresponding to the $S=5 / 2$ $[4 \mathrm{Fe}-4 \mathrm{~S}]_{\text {aux }}[(\mathrm{Cys}) \mathrm{Fe}]$ form. Thus, Cys addition induces transformation of the various $[4 \mathrm{Fe}]_{\mathrm{aux}}$ and $[5 \mathrm{Fe}]_{\mathrm{aux}}$ forms to the $[4 \mathrm{Fe}-4 \mathrm{~S}]_{\mathrm{aux}}[(\mathrm{Cys}) \mathrm{Fe}]$ form. Addition of Hcy affects several of the minor EPR signals (as would be expected for addition of a thiol to an $\mathrm{Fe}-\mathrm{S}$ cluster enzyme; Figure 2, sample 4), but importantly does not regenerate the distinctive $S=$ $5 / 2$ signal that is observed in typical, as-isolated HydG samples (Figure 1A). ${ }^{13}$ This set of HydG samples therefore comprises the four samples needed to distinguish the models in Scheme 2.

FTIR spectroscopy is the only reported assay for $\left[\mathrm{Fe}-(\mathrm{CO})_{2}(\mathrm{CN})\right]$ synthon formation. ${ }^{11,20}$ When HydG is mixed with ${ }^{13} \mathrm{C}_{9}$-Tyr, SAM, and DTH, an $[\mathrm{Fe}(\mathrm{CO})(\mathrm{CN})]$ intermediate ("Complex A") is initially generated and subsequently transformed into a second species ("Complex B") with the formula $\left[\mathrm{Fe}(\mathrm{CO})_{2}(\mathrm{CN})\right] .{ }^{11}$ FTIR spectra acquired $>100 \mathrm{~s}$ after initiating the HydG reaction typically show a mixture of Complexes A and B (Figure 1B). In this study, we use the intensity of the $v\left({ }^{13} \mathrm{CO}\right)=2010 \mathrm{~cm}^{-1}$ mode that corresponds to Complex $\mathrm{B}$ as an assay for $\left[\mathrm{Fe}-(\mathrm{CO})_{2}(\mathrm{CN})\right]$ product formation; ${ }^{21}$ similar results are obtained when using the $v\left({ }^{13} \mathrm{CO}\right)=1960 \mathrm{~cm}^{-1}$ mode (see Figure $\left.\mathrm{S} 1\right)$.

Mixing sample 1 with SAM and ${ }^{13} \mathrm{C}_{9}$-Tyr results in no Complex B formation, as determined by FTIR spectroscopy (Figure 3). This demonstrates that the dangler Fe is integral for $\left[\mathrm{Fe}(\mathrm{CO})_{2}(\mathrm{CN})\right]$ synthon formation. Both samples 2 and 4 generate a small amount of Complex B with qualitatively similar kinetic profiles; additional $\left[\mathrm{Fe}(\mathrm{CO})_{x}(\mathrm{CN})_{y}\right]$ species are 
not observed within the detection limit of the experiment (other than Complex A). On the other hand, sample 3 yields strong signals corresponding to Complex B that are consistent with previous findings. ${ }^{11}$ Thus, the $[4 \mathrm{Fe}-4 \mathrm{~S}]_{\mathrm{aux}}[(\mathrm{Cys}) \mathrm{Fe}]$ form, which is the major auxiliary cluster form in sample 3 and a minor form in samples 2 and 4, is clearly implicated in $\left[\mathrm{Fe}(\mathrm{CO})_{2}(\mathrm{CN})\right]$ product formation. Moreover, the other $[5 \mathrm{Fe}]_{\mathrm{aux}}$ forms present in sample 2 are not sufficient for generating high yields of Complex B, and unlike Cys, Hcy does not significantly restore activity for Complex B formation. Similar conclusions may be drawn by analyzing Complex A formation using the $v\left({ }^{13} \mathrm{CO}\right)=1906 \mathrm{~cm}^{-1}$ mode (see Figure S2) or by repeating the experiment with a different batch of Cys-deficient HydG (see Figure S3). These findings collectively point to the requirement of a $[4 \mathrm{Fe}-4 \mathrm{~S}]_{\mathrm{aux}}[(\mathrm{Cys}) \mathrm{Fe}]$ cluster for $\left[\mathrm{Fe}(\mathrm{CO})_{2}(\mathrm{CN})\right]$ product formation.

It is also noteworthy that the relative intensity of the $v\left({ }^{13} \mathrm{CN}\right)$ signals $(\mathrm{s})$ to the $v\left({ }^{13} \mathrm{CO}\right)$ signals is higher in samples 2 and 4 compared with sample 3 . This indicates the presence of additional $\mathrm{CN}^{-}$-containing species such as $[4 \mathrm{Fe}-4 \mathrm{~S}]_{\mathrm{aux}}[\mathrm{CN}]$ (which has been previously identified by EPR spectroscopy), ${ }^{13}$ other Fe-CN complexes, and/or free $\mathrm{CN}^{-}$. The greater relative quantities of these species in samples 2 and 4 may be attributed to enzyme forms that are not active for $\left[\mathrm{Fe}(\mathrm{CO})_{2}(\mathrm{CN})\right]$ product generation but are nonetheless capable of adventitious $\mathrm{CN}^{-}$production. ${ }^{11,14,17,22}$ In addition, the yields of Complex B in samples 2 and 4 are lower than what would be predicted based on the EPR data, which suggest that these samples contain up to $\sim 30 \%$ of the $[4 \mathrm{Fe}-4 \mathrm{~S}]_{\text {aux }}[(\mathrm{Cys}) \mathrm{Fe}]$ form relative to sample 3 and should therefore generate up to $\sim 30 \%$ as much Complex B. Moreover, the kinetic profile of Complex B formation is different between sample 3 and samples 2 and 4. Determining the origin of these differences will be the subject of future work. Regardless of the reason for the unexpectedly low product quantities observed in samples 2 and 4, these findings indicate that the $[4 \mathrm{Fe}-4 \mathrm{~S}]_{\mathrm{aux}}[(\mathrm{Cys}) \mathrm{Fe}]$ structure is required for generating the $\left[\mathrm{Fe}(\mathrm{CO})_{2}(\mathrm{CN})\right]$ product.

In conclusion, we have linked the starting Fe-S cluster content of HydG with the activity of HydG toward $\left[\mathrm{Fe}(\mathrm{CO})_{2}(\mathrm{CN})\right]$ synthon formation, showing that both Cys and the dangler Fe in the $[4 \mathrm{Fe}-4 \mathrm{~S}]_{\mathrm{aux}}[(\mathrm{Cys}) \mathrm{Fe}]$ cluster form are required for this process. This supports the proposal that a $\left[(\mathrm{Cys}) \mathrm{Fe}(\mathrm{CO})_{2}(\mathrm{CN})\right]^{-}$complex is built on the $\mathrm{HydG}$ auxiliary cluster and is a central intermediate in $[\mathrm{FeFe}]$-hydrogenase H-cluster maturation. ${ }^{13}$ This work also highlights the importance of determining the auxiliary cluster structure when interpreting biochemical or spectroscopic data on $\mathrm{HydG}$, particularly because several auxiliary cluster forms may allow for the generation of byproducts and/or intermediates such as $p$-cresol, glyoxylate, $\mathrm{CN}^{-}$, formate, and $\mathrm{CO}$, but only the $[4 \mathrm{Fe}-4 \mathrm{~S}]_{\mathrm{aux}}[(\mathrm{Cys}) \mathrm{Fe}]$ structure leads to $\left[\mathrm{Fe}(\mathrm{CO})_{2}(\mathrm{CN})\right]$ product formation.

\section{Supplementary Material}

Refer to Web version on PubMed Central for supplementary material.

\section{Acknowledgments}

Funding from the National Institute of General Medical Sciences of the National Institutes of Health (F32GM111025 to D.L.M.S., R01GM65440 to S.P.C., and R01GM104543 to R.D.B.), the Division of Materials 
Science and Engineering of the Department of Energy (DE-FG02-09ER46632 to J.R.S.) for discussions, protein preparation, and manuscript editing, and the Department of Education (P200A120187 to C.C.P.).

\section{REFERENCES}

1. Vincent KA, Parkin A, Armstrong FA. Chem. Rev. 2007; 107:4366-4413. [PubMed: 17845060]

2. Posewitz MC, King PW, Smolinski SL, Zhang L, Seibert M, Ghirardi ML. J. Biol. Chem. 2004; 279:25711-25720. [PubMed: 15082711]

3. Broderick JB, Byer AS, Duschene KS, Duffus BR, Betz JN, Shepard EM, Peters JW. JBIC, J. Biol. Inorg. Chem. 2014; 19:747-757. [PubMed: 24972661]

4. Broderick JB, Duffus BR, Duschene KS, Shepard EM. Chem. Rev. 2014; 114:4229-4317. [PubMed: 24476342]

5. Pilet E, Nicolet Y, Mathevon C, Douki T, Fontecilla-Camps JC, Fontecave M. FEBS Lett. 2009; 583:506-511. [PubMed: 19166853]

6. Nicolet Y, Zeppieri L, Amara P, Fontecilla-Camps JC. Angew. Chem., Int. Ed. 2014; 53:11840 11844.

7. Kuchenreuther JM, Myers WK, Stich TA, George SJ, Nejatyjahromy Y, Swartz JR, Britt RD. Science. 2013; 342:472-475. [PubMed: 24159045]

8. Driesener RC, Challand MR, McGlynn SE, Shepard EM, Boyd ES, Broderick JB, Peters JW, Roach PL. Angew. Chem., Int. Ed. 2010; 49:1687-1690.

9. Shepard EM, Duffus BR, George SJ, McGlynn SE, Challand MR, Swanson KD, Roach PL, Cramer SP, Peters JW, Broderick JB. J. Am. Chem. Soc. 2010; 132:9247-9249. [PubMed: 20565074]

10. Kuchenreuther JM, George SJ, Grady-Smith CS, Cramer SP, Swartz JR. PLoS One. 2011; 6:e20346. [PubMed: 21673792]

11. Kuchenreuther JM, Myers WK, Suess DLM, Stich TA, Pelmenschikov V, Shiigi S, Cramer SP, Swartz JR, Britt RD, George SJ. Science. 2014; 343:424-427. [PubMed: 24458644]

12. Dinis P, Suess DLM, Fox SJ, Harmer JE, Driesener RC, De La Paz L, Swartz JR, Essex JW, Britt RD, Roach PL. Proc. Natl. Acad. Sci. U. S. A. 2015; 112:1362-1367. [PubMed: 25605932]

13. Suess DLM, Bürstel I, De La Paz L, Kuchenreuther JM, Pham CC, Cramer SP, Swartz JR, Britt RD. Proc. Natl. Acad. Sci. U. S. A. 2015; 112:11455-11460. [PubMed: 26324916]

14. Pagnier A, Martin L, Zeppieri L, Nicolet Y, Fontecilla-Camps JC. Proc. Natl. Acad. Sci. U. S. A. 2016; 113:104-109. [PubMed: 26699472]

15. Kuchenreuther JM, Grady-Smith CS, Bingham AS, George SJ, Cramer SP, Swartz JR. PLoS One. 2010; 5:e15491. [PubMed: 21124800]

16. Kuchenreuther JM, Britt RD, Swartz JR. PLoS One. 2012; 7:e45850. [PubMed: 23049878]

17. Driesener RC, Duffus BR, Shepard EM, Bruzas IR, Duschene KS, Coleman NJR, Marrison APG, Salvadori E, Kay CWM, Peters JW, Broderick JB, Roach PL. Biochemistry. 2013; 52:8696-8707. [PubMed: 24206022]

18. Suess DLM, Britt RD. Top. Catal. 2015; 58:699-707.

19. Rubach JK, Brazzolotto X, Gaillard J, Fontecave M. FEBS Lett. 2005; 579:5055-5060. [PubMed: 16137685]

20.

Assays for SAM cleavage (e.g., formation of the $5^{\prime}$-dAH byproduct) or other steps that occur prior to $\left[\mathrm{Fe}(\mathrm{CO})_{2}(\mathrm{CN})\right]$ synthon formation (e.g., formation of the 4-hydroxybenzyl radical, $p$-cresol, glyoxylate, $\mathrm{CN}^{-}$, formate, and/or $\mathrm{CO}$ ) yield important mechanistic insights but are not necessarily sufficient for demonstrating activity for $\left[\mathrm{Fe}(\mathrm{CO})_{2}(\mathrm{CN})\right]$ synthon formation.

21.

Note that although we formulate Complex B as a $\left[(\mathrm{Cys}) \mathrm{Fe}(\mathrm{CO})_{2}(\mathrm{CN})\right]^{-}$complex, it is unclear whether the spectroscopically observed form of this complex is directly bound to the $[4 \mathrm{Fe}-4 \mathrm{~S}]_{\mathrm{aux}}$ cluster, unbound to the $[4 \mathrm{Fe}-4 \mathrm{~S}]_{\text {aux }}$ cluster but within the protein environment, or in solution.

22. Nicolet Y, Martin L, Tron C, Fontecilla-Camps JC. FEBS Lett. 2010; 584:4197-4202. [PubMed: 20837009]

J Am Chem Soc. Author manuscript; available in PMC 2016 March 01. 

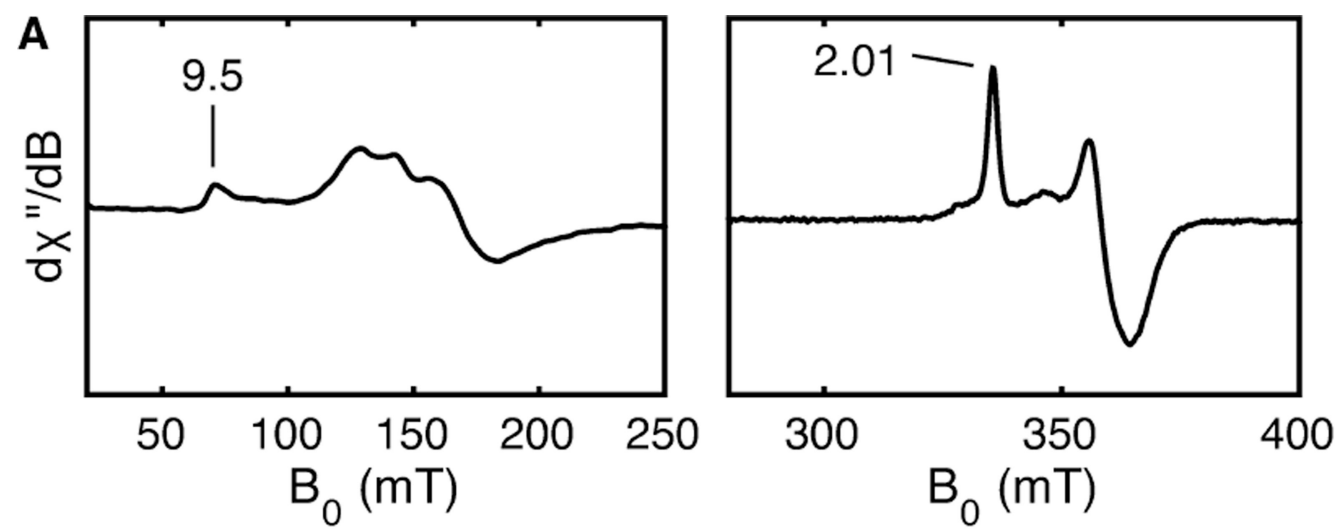

$$
\begin{gathered}
S=5 / 2 \\
{[4 \mathrm{Fe}-4 \mathrm{~S}]_{\text {aux }}[(\text { Cys }) \mathrm{Fe}]} \\
S=1 / 2 \\
{[4 \mathrm{Fe}-4 S]_{\mathrm{RS}}}
\end{gathered}
$$

B

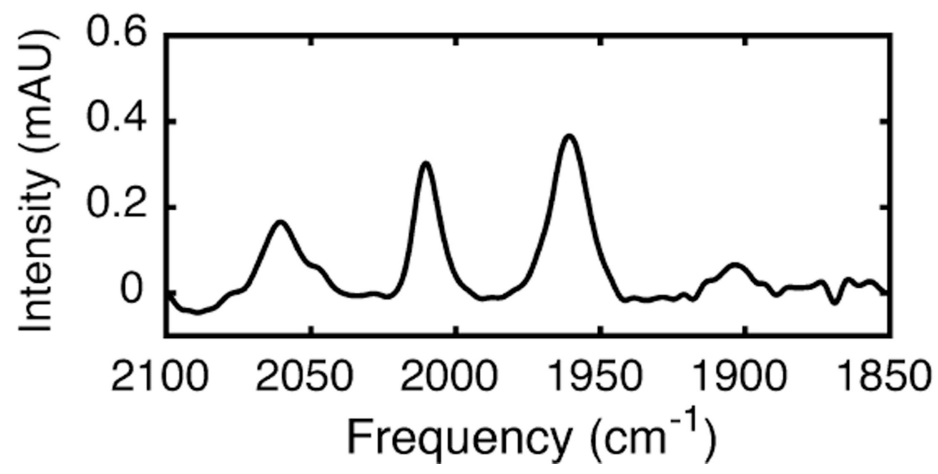

Complex A

$v\left({ }^{13} \mathrm{CO}\right)=1906$

$v\left({ }^{13} \mathrm{CN}\right)=2048$

Complex B

Figure 1.

Typical EPR spectra (A) of as-isolated HydG. Experimental parameters: $9.4 \mathrm{GHz}, 10 \mathrm{~K}, 5$ $\mathrm{mW}$ (left panel) or $126 \mu \mathrm{W}$ (right panel). Typical FTIR spectrum (B) of HydG after reacting with ${ }^{13} \mathrm{C}_{9}$-Tyr, SAM, and DTH for $1200 \mathrm{~s}$. 

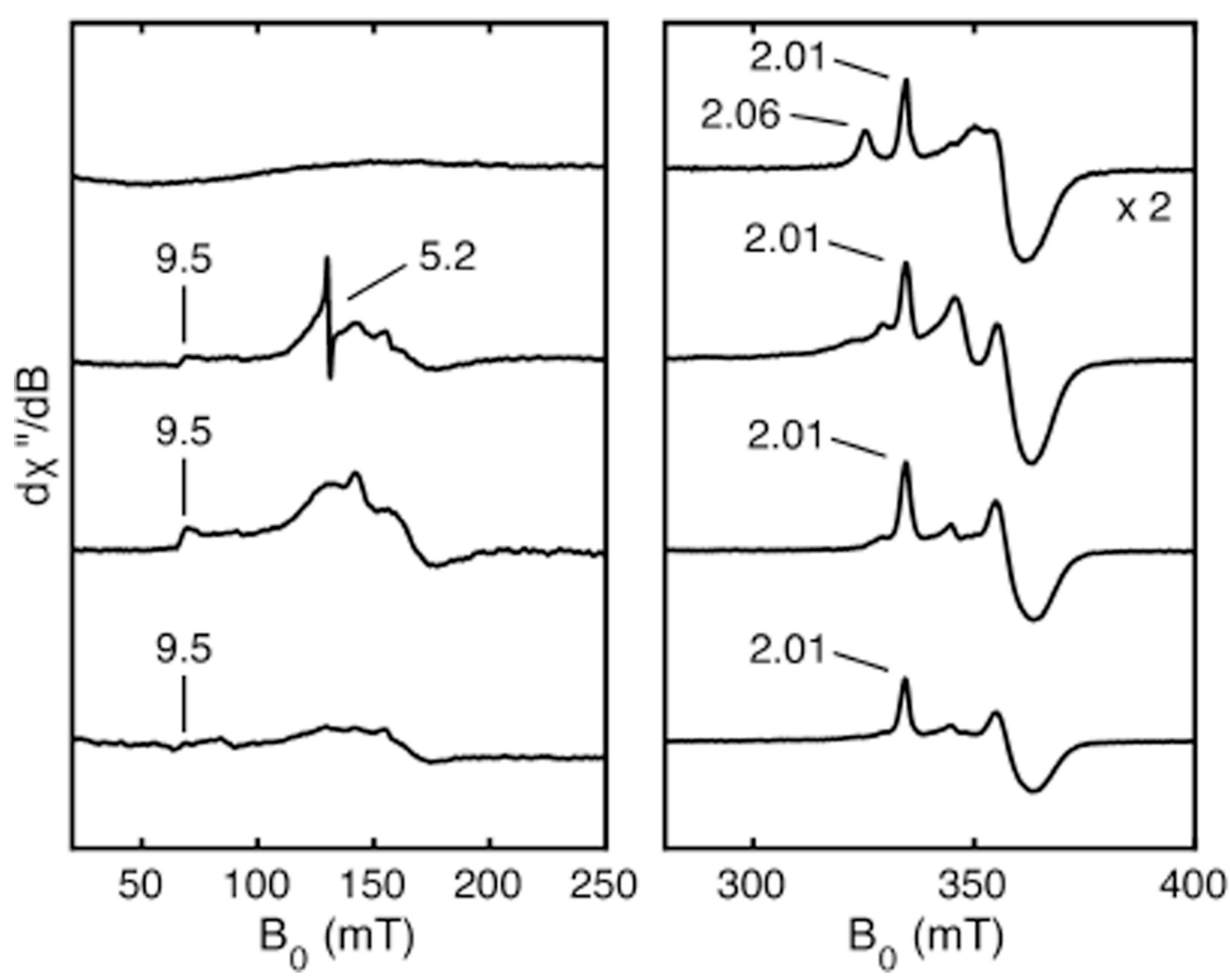

Sample Additives

1

DTH, SAM, Cys, EDTA

2

DTH, SAM,

3

DTH, SAM, Cys

Figure 2.

EPR spectra of HydG samples 1-4. Experimental parameters: $9.4 \mathrm{GHz}, 10 \mathrm{~K}, 5 \mathrm{~mW}$ (left panel) or $126 \mu \mathrm{W}$ (right panel). 

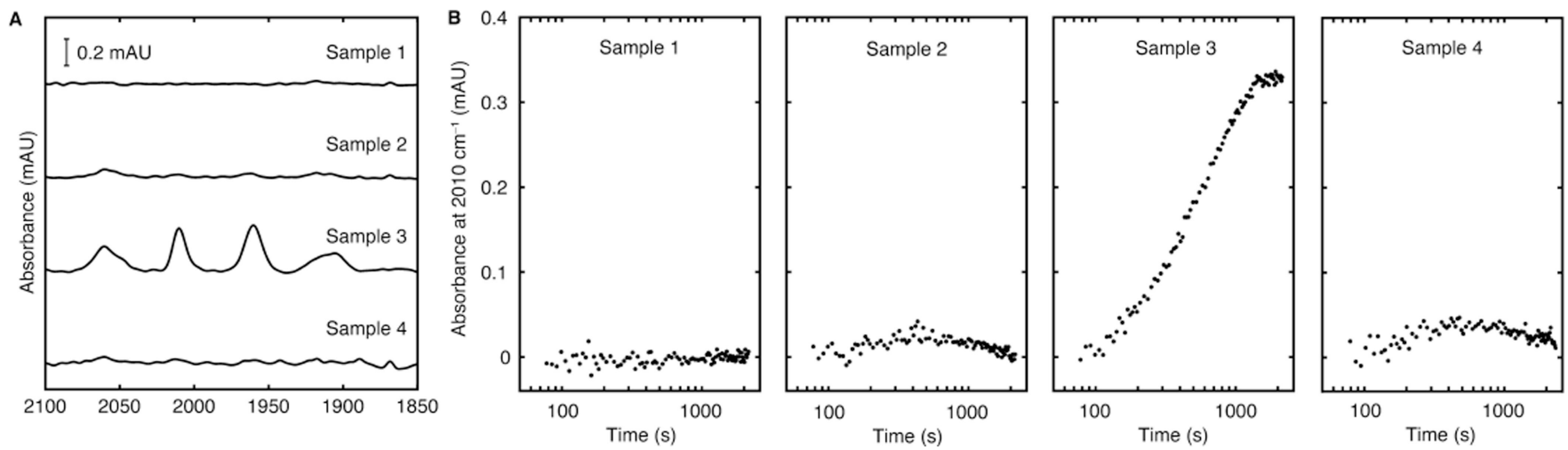

Figure 3.

Comparison of Complex B formation in HydG samples 1-4 using ${ }^{13} \mathrm{C}_{9}$-Tyr and the additives listed in Figure 2. Spectra (A) recorded at $1200 \mathrm{~s}$. Time evolution of Complex B formation (B). 
A<smiles>N[C@@H](Cc1ccc(O)cc1)C(=O)O</smiles>

Fe (from HydG) apo-HydA HydE HydF HydG

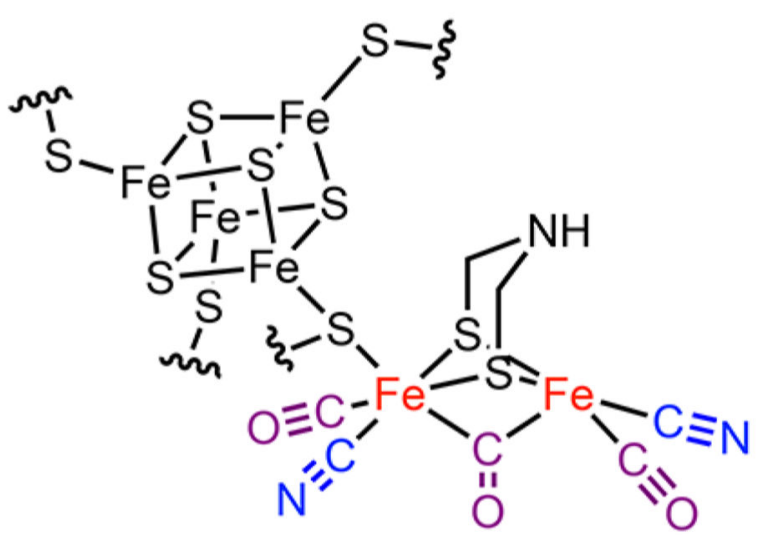
holo-HydA

B

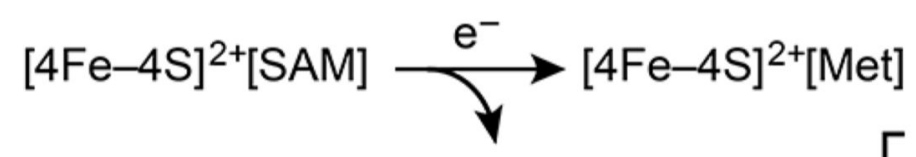<smiles>N[C@@H](Cc1ccc(O)cc1)C(=O)O</smiles>

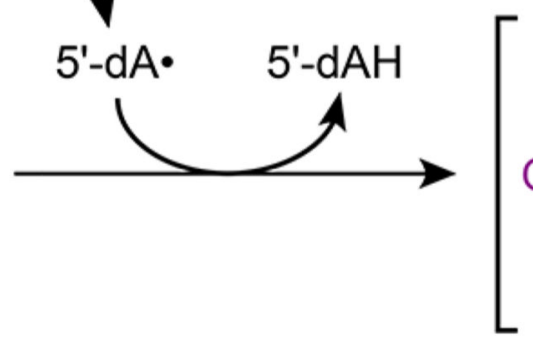<smiles>N[C@@H](Cc1ccc(O)cc1)C(=O)O</smiles><smiles>C[CH]C</smiles><smiles>Cc1ccc(O)cc1</smiles>

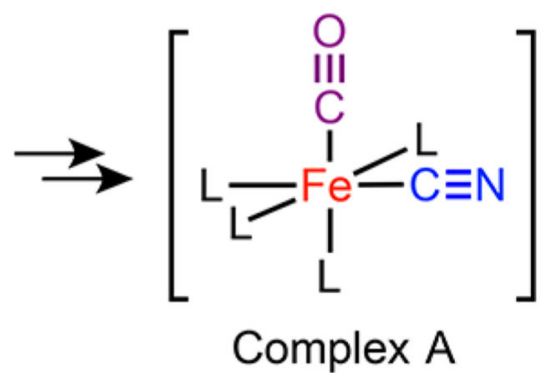

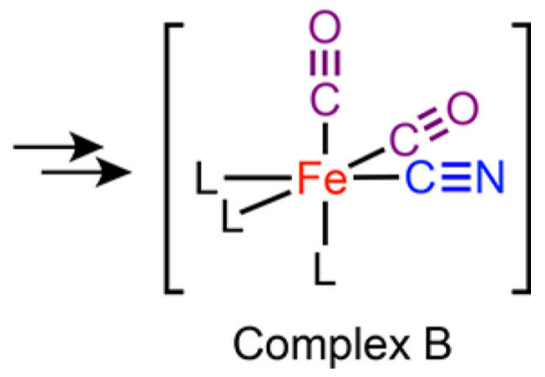

Scheme 1. 
(a) Sample 1
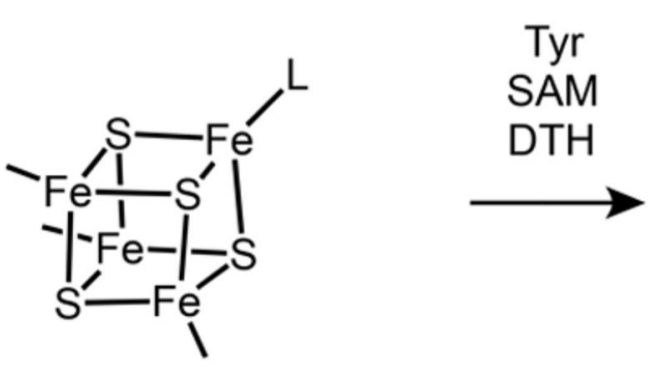

(b) Sample 2

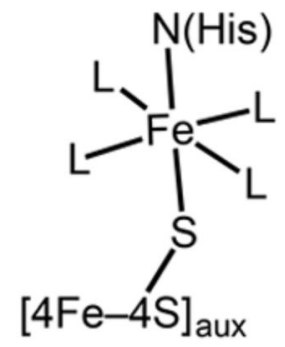

(c) Sample 3

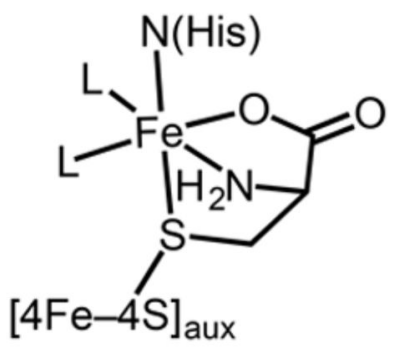

(d) Sample 4

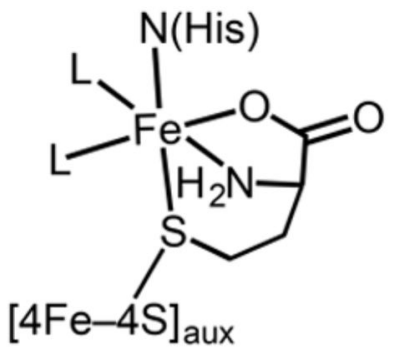

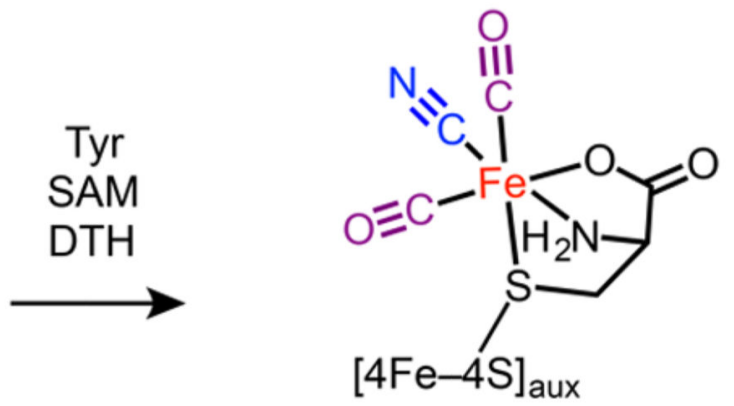
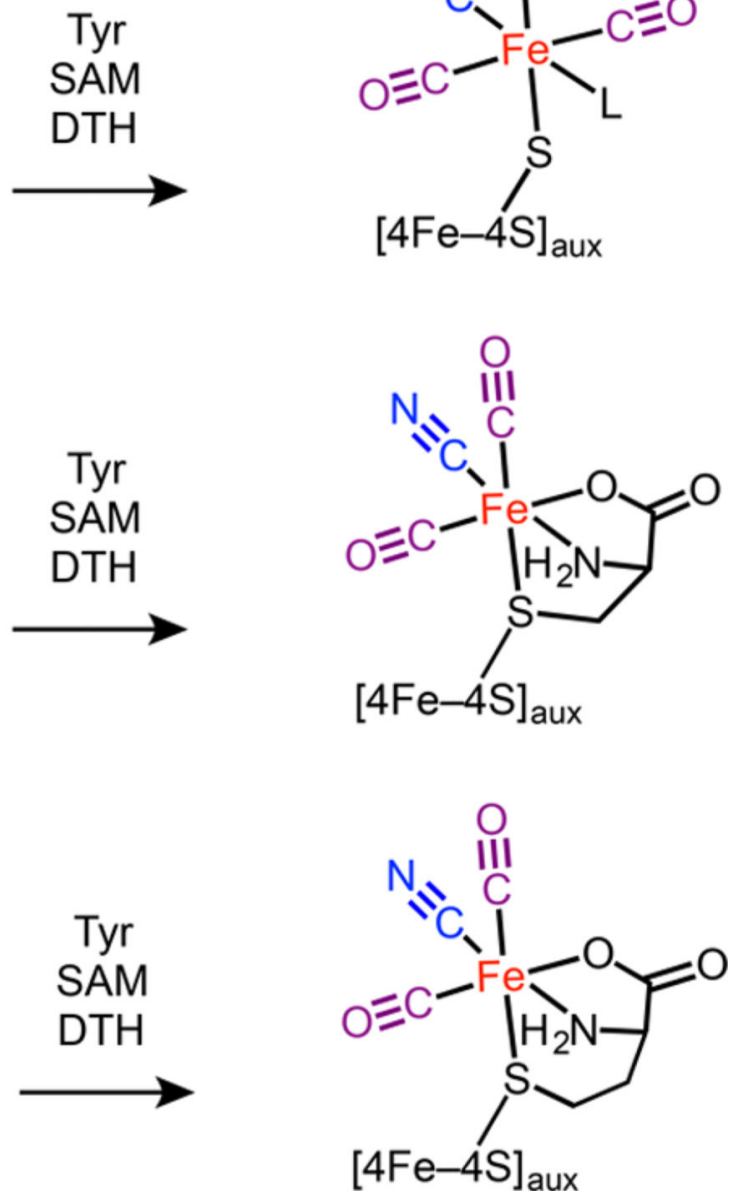

Scheme $2^{\mathrm{a}}$

${ }^{a}$ Note: only one stereoisomer is shown for each $\left[\mathrm{Fe}(\mathrm{CO})_{2}(\mathrm{CN})\right]$ complex. 